\title{
Online MR evaluation of inter- and intra-fraction uterus motions and bladder volume changes during cervical cancer external beam radiotherapy
}

Xu Li ${ }^{\dagger}$, Lizhen Wang ${ }^{\dagger}$, Zhen Cui, Yukun Li, Pei Liu, Yungang Wang, Jinhong Zhu, Jianmin Zhu, Yong Yin ${ }^{*}$ and Zhenjiang Li*

\begin{abstract}
Purpose/objective(s): The purpose of the study was to assess the uterus motions and bladder volume changes of fractional movements in cervical sites throughout the external beam radiotherapy (EBRT) treatment.

Materials/methods: A prospective online MR imaging tracking study was conducted in EBRT 43 patients with at least 4 scans during each treatment (before: ultrasound scan, MRI scan, CBCT scan, after: MRI scan) were included. In order to improve the treatment repeatability, each patient was instructed to empty the bladder and drink $500 \mathrm{ml}$ water $1 \mathrm{~h}$ before $\mathrm{CT}$ simulation and each treatment. If the ultrasound scan result reached the CT simulation volume of bladder, the treatment began. Bladder was outlined on the T2 weighted axial sequence and CBCT image by the two observers to avoid the influence of contouring. The data of bladder volume and scanning time were accurately recorded. The bladder volumes, filling rates and uterus motion were retrospectively analyzed by MIM software.
\end{abstract}

Results: Inter-fraction variation of the bladder volume was significant $(p<0.0001)$. Intra-fraction mean increase of the bladder volume was modest $(30 \mathrm{cc})$ but significant $(p<0.001)$. Both inter- and intra-fraction of the uterus motion were significant. The average time between the pre-and post-fraction MRI scans was $27.82 \pm 7.12 \mathrm{~min}$ (range 10-55 min) for IMRT plans and 24.14 $\pm 5.86 \mathrm{~min}$ (range7-38 min) for VMAT plan. Average bladder filling rate was $3.43 \mathrm{ml} / \mathrm{min}$. The bladder filling rate did not change significantly with the course of treatment, but the bladder was more intolerant.

Conclusion: This is the most detailed assessment of intra-fraction and inter-fraction motion during EBRT for cervical cancer. Finally, this study will inform appropriate treatment margins for online adaptive radiotherapy. We suggest that at least one image scan is needed before the EBRT. The portable US scanner provides a quick but unreliable measurement of the bladder volume. There is a significant statistical difference between the results of ultrasonic scanning and that of image scanning.

Keywords: Online MRI, EBRT, Bladder filling, Inter-fractional and Intra-fractional bladder motion

*Correspondence: yinyongsd@126.com; Izjsdsfdx@126.com

${ }^{\dagger}$ Xu Li and Lizhen Wang have contributed equally to this work

Department of Radiation Oncology Physics and Technology, Shandong

Cancer Hospital and Institute, Shandong First Medical University

and Shandong Academy of Medical Sciences, No.440 Jiyan road, Huaiyin

district, Jinan City 250117, Shandong Province, China

Xu Li and Lizhen Wang have authors share first authorship

\section{Introduction}

The EBRT plays an important role in the treatment of locally advanced cervical cancer [1]. During EBRT for cervical cancer, a larger planned target volume was needed to include potential organ movement during treatment. But these huge profits promote the treatment 


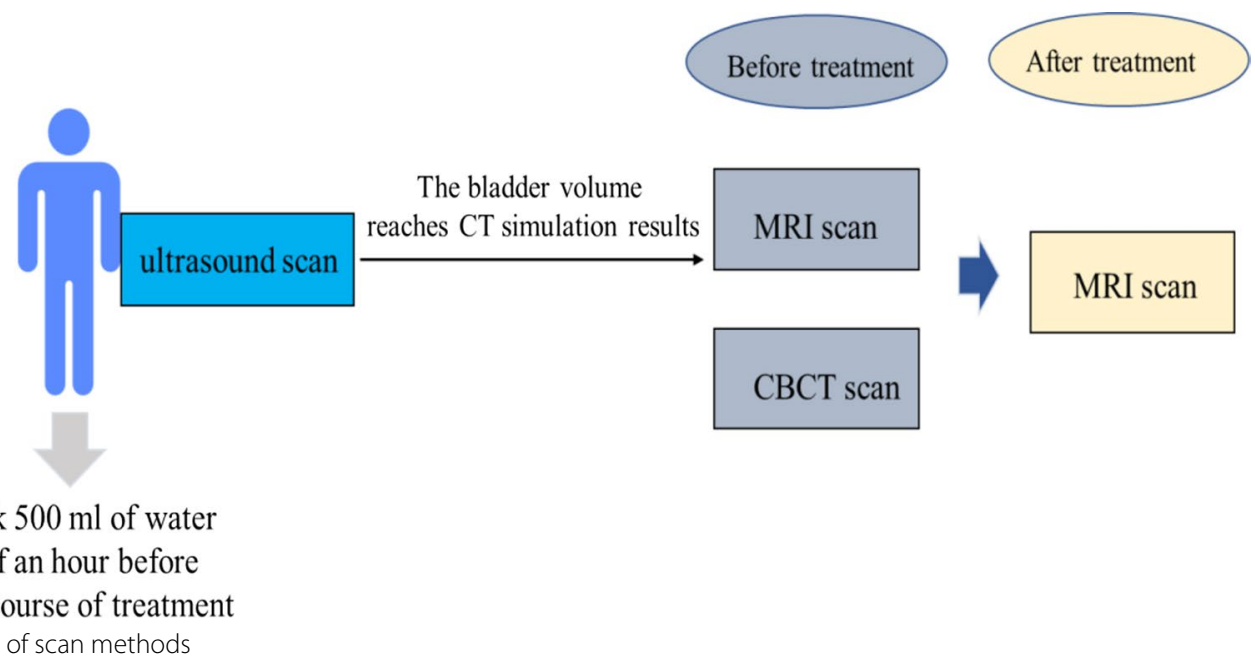

toxicity [2]. The introduction of online adaptive MRguided EBRT will adapt the plan to the daily anatomical position, but the effect of bladder motion for cervical cancer was not certain [3].

The radiotherapy process of cervical cancer is usually long, the difference of organ movement between different parts has a greater impact on the accuracy of dose delivery [4]. At the same time, population-based standard marginal therapy is ineffective for cervical cancer due to significant differences in the degree and complexity of cervical and uterine movement between patients. Several studies have found that the uterus and cervix can significantly move and disappear during treatment [5-7]. In order to improve the coverage of the target area, the planned target volume around the CTV is to ensure geometric uncertainty during treatment.

Unfortunately, knowledge of what constitutes an appropriate planning margin is currently limited. Although many authors and many methods, such as cone beam computed tomography (CBCT), have extensively studied bladder movement between fractional stages and within fractional levels, there has not been much verification of repeatability and reliability [8-10].

At our clinic, an image-guided cervical radiotherapy protocol is underway that includes pretreatment ultrasound scan as well as intra-fraction positional measurements of the bladder. Pretreatment CBCTs and MRI-scans are acquired at each fraction and include bladder information. But the bladder volume information after treatment is not clear. The purpose of this study is therefore to compare and quantify inter-and intrafraction bladder volume and uterus position variation during EBRT of cervical cancer by different measured techniques.

\section{Methods and materials}

\section{Patients and treatment}

Forty-three patients with locally advanced cervical cancer patients were prospectively included in this study. The distribution of FIGO (International Federation of Gynaecology and Obstetrics) stages was as follows: IB: 3 patients, IIA: 3 patients, IIB: 6 patients, IIIA: 12 patients, IIIB: 15 patients, and IV:4 patients. The patients' ages ranged from 26 to 67 years (median 49). Radiotherapy combined external beam radiotherapy (EBRT) with brachytherapy delivered in the last 1-2 weeks of EBRT [11]. For 13 patients, radiotherapy was combined with either chemotherapy. The doses at the ICRU reference point were 46 or $50 \mathrm{~Gy}$, which were delivered in 23 or 25 daily fractions of 2 Gy (4-5 weeks of full treatment course). In an attempt to achieve day-to-day reproducibility in bladder filling, the patients were asked to drink $500 \mathrm{ml}$ of water $1 \mathrm{~h}$ prior to each EBRT treatment fraction (Fig. 1). Patients were treated in supine position on a belly board and with a foot rest.

\section{Data acquisition and delineation}

In each session of each patient, five scans were obtained at different points in time. The first image scan was CT simulation. As for the simulation, patients are required to drink $500 \mathrm{ml}$ of water an hour before simulation. In order to achieve consistent results, before $\mathrm{CT}$ simulation acquisition, the bladder volume was measured using a portable bladder US scanner. Simulation scan starts only when the volume of the bladder reaches CT simulation standard, and the corresponding volume measurement is carried out by portable US scanner. As for daily treatment, patients were also asked to drink $500 \mathrm{ml}$ of water $1 \mathrm{~h}$ prior to each session. The volume of bladder was detected 
Table 1 Variations in bladder volume and filling rate

\begin{tabular}{|c|c|c|c|c|}
\hline & \multicolumn{2}{|l|}{ IMRT } & \multicolumn{2}{|l|}{ VMAT } \\
\hline & Pre-treatment & Post-treatment & Pre-treatment & Post-treatment \\
\hline & Mean & & Mean & \\
\hline Volume (ml) & 335.16 & 419.67 & 268.39 & 359.03 \\
\hline Vpre - Vpost (ml) & 84.51 & & 90.63 & \\
\hline $\mathrm{dV} / \mathrm{dt}(\mathrm{ml} / \mathrm{min})$ & 3.18 & & 4.03 & \\
\hline
\end{tabular}

by portable US scanner before each treatment. When the volume of bladder reaches $\mathrm{CT}$ simulation standard, the treatment process started. MRI scan is performed when the urine volume meets the requirements (the same bladder volume as CT simulation), which was scanned by ultrasound. This study uses fast pelvic MRI sequence, the scan time is $2 \mathrm{~min}$. The scanning parameters of Unity are ACQ matrix $=268 \times 267, \mathrm{FOV}=400 \times 400 \mathrm{~mm}$, $\mathrm{TR}=1532 \mathrm{~ms}, \mathrm{TE}=278 \mathrm{~ms}$. After acquisition of this MRI scan, the patient is asked to do radiotherapy. Before radiotherapy, the $\mathrm{CBCT}$-scan was performed. After the radiotherapy, the MRI-scan were did again by using the same MRI sequence. The bladder wall was delineated by two experienced radiographers on planning CT-scan and each pre- CBCT-scan, MRI-scan and post MRI-scan by using Monaco 5.40.01 version treatment planning system (TPS).

\section{Analysis of bladder volume and position change}

Bladder volume change rate and uterus motion were analyzed by separately. Bladder volumes were calculated by the manual delineation data. The volume increase was calculated by CBCT scan and MRI scans, and the pretreatment bladder volume was subtracted from the posttreatment volume. The filling rate was then calculated by dividing the volume increase by the time between pre-treatment scans and post-scan MRI scan recorded by the device. Bladder volume change rate and uterus motion were analyzed by using MIM software (the version was 7.0.4).

\section{Statistics}

The statistics of bladder volumes and uterus motion was based on CBCT-scan bladders, MRI-scan bladders, and the planning CT bladders. Statistics of the variations for the population of patients was calculated as follows: The group mean value was calculated as the average value of each patient, and the systematic error $(\mathrm{P})$ was the standard deviation (SD) of the average value per patient. The root mean square error ( $r$ ) of all SD patients in all scores of each patient was calculated. We tested whether group statistics significantly differed between the different scan groups. Mean inter-fraction bladder movement was compared using an independent-samples t-test.

\section{Results}

The mean time between the pre-and post-fraction MRI scans was $27.82 \pm 7.12 \mathrm{~min}$ (range $10-55 \mathrm{~min}$ ) for IMRT plans and 24.14 $\pm 5.86 \mathrm{~min}$ (range7-38 $\mathrm{min}$ ) for VMAT plan. A summary of the results can be found in Table 1. As the Fig. 2 showed that there is no statistical difference $(\mathrm{p}=0.5312)$ in bladder volume pre- and post-treatment
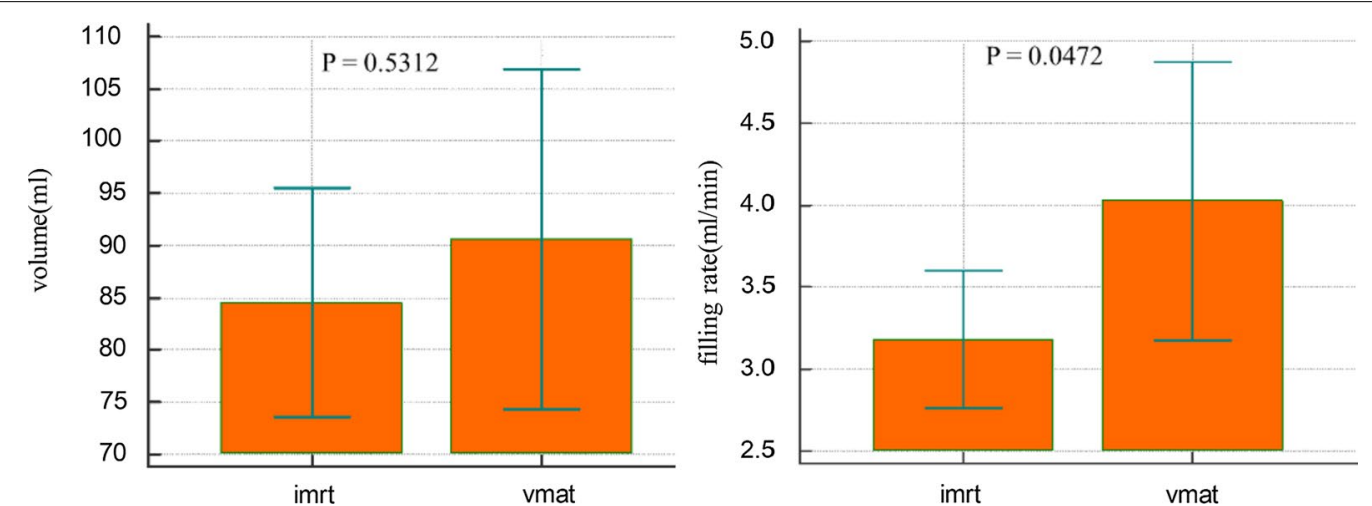

Fig. 2 There is no statistical difference $(p=0.5312)$ in bladder volume pre- and post treatment in imrt and vmat treat mode. The bladder filling rate is statistically different between imrt and vmat $(p=0.0472)$ 
in imrt and vmat treat mode. The bladder filling rate is statistically different between imrt and vmat $(\mathrm{p}=0.0472)$. A total of 215 CBCT-scans, 476 MRI-scans, 281 Ultrasound-scan and 43 planning CT-scans were analyzed. All patients were able to follow all treatment flow. The bladders were delineated in all scans except ultrasound scans.

\section{Inter-fraction volume and position variation}

A summary of the results can be found in Table 2 and Fig. 3. Bladder filling rate was $3.43 \pm 3.05 \mathrm{ml} / \mathrm{min}$ over all treatment fractions. A significant positive correlation was found between bladder filling rate and volume of the bladder at the start of a fraction, as measured in the prefraction MRI scan $(\mathrm{r}=0.46, \mathrm{p}<0.01)$. This means that a larger bladder volume observed at the start of treatment was predictive of a higher inflow rate. Regression analysis showed a constant of 1.5 and a coefficient of 0.007 , which means that for every $100 \mathrm{ml}$ extra bladder volume at the start of treatment, the inflow rate increased with approximately $0.7 \mathrm{ml} / \mathrm{min}$. As shown in Fig. 4, the bladder volume in plan CT is statistically different from the volume measured by ultrasound $(\mathrm{p}=0.0336)$, and the volume measured by ultrasound is statistically different from the volume before treatment $(\mathrm{p}<0.0001)$, but there is no statistical difference between the ultrasound results and after treatment $(\mathrm{p}=0.2595)$.

Bladder volume increased on average by $86.37 \pm 70.63$ over all treatment fractions. The median bladder volume increase rate of the whole group was $3.43 \mathrm{ml} / \mathrm{min}$, with an intra-patient $\mathrm{SD}$ of $3.05 \mathrm{ml} / \mathrm{min}$. As the treatment progresses, the rate of bladder volume change gradually decreases(from $3.68 \pm 3.33$ to $2.33 \pm 2.30 \mathrm{ml} / \mathrm{min}$, $\mathrm{p}<0.05$ ). The Vus(the volume of US scanner measured)

Table 2 Variations in bladder volume for all patients. The group $x$ means number of treatments $(x-1) * 5+1 \sim(x-1) * 5+5$

\begin{tabular}{|c|c|c|c|c|c|c|c|c|c|c|c|c|c|c|}
\hline & \multicolumn{2}{|c|}{ All patients } & \multicolumn{2}{|c|}{ Group1 (1-5) } & \multicolumn{2}{|c|}{ Group2 (6-10) } & \multicolumn{2}{|l|}{$\begin{array}{l}\text { Group3 } \\
(11-15) \\
\end{array}$} & \multicolumn{2}{|l|}{$\begin{array}{l}\text { Group4 } \\
(16-20) \\
\end{array}$} & \multicolumn{2}{|c|}{ Group5 (21-25) } & \multicolumn{2}{|c|}{ Group6 (26-30) } \\
\hline & Mean & $\sigma$ & Mean & $\sigma$ & Mean & $\sigma$ & Mean & $\sigma$ & Mean & $\sigma$ & Mean & $\sigma$ & Mean & $\sigma$ \\
\hline Treat time (ml) & 26.84 & 6.94 & 27.65 & 8.20 & 27.18 & 7.29 & 27.00 & 6.87 & 26.34 & 5.59 & 23.96 & 4.76 & 28.69 & 5.72 \\
\hline Vpre - Vplan (ml) & -96.88 & 143.46 & -97.98 & 169.11 & -92.52 & 139.66 & -75.33 & 141.14 & -99.89 & 99.52 & -112.27 & 155.17 & -140.72 & 112.66 \\
\hline Vpost - Vplan (ml) & -10.52 & 152.88 & -2.64 & 176.17 & 8.02 & 154.22 & 13.94 & 146.09 & -24.87 & 113.13 & -46.57 & 154.85 & -81.56 & 125.96 \\
\hline Vus - Vpre (ml) & 77.25 & 86.76 & 61.29 & 106.78 & 75.77 & 81.26 & 84.24 & 81.87 & 75.37 & 59.81 & 98.62 & 87.79 & 98.15 & 69.24 \\
\hline Vplan - Vus (ml) & 19.63 & 148.89 & 36.69 & 160.11 & 16.74 & 145.36 & -8.91 & 158.96 & 24.52 & 98.93 & 13.65 & 178.22 & 42.56 & 126.19 \\
\hline Vpre - Vus (ml) & 9.11 & 116.47 & 34.05 & 140.01 & 24.76 & 105.70 & 5.02 & 123.70 & -0.34 & 88.27 & -32.92 & 93.74 & -39.00 & 77.48 \\
\hline Vpost - Vpre (ml) & 86.37 & 70.63 & 95.34 & 83.17 & 100.54 & 65.21 & 89.27 & 81.27 & 75.02 & 58.02 & 65.70 & 39.35 & 59.15 & 50.60 \\
\hline$(V p o s t-V p r e) / d t$ & 3.43 & 3.05 & 3.68 & 3.33 & 4.26 & 4.03 & 2.34 & 1.76 & 2.93 & 2.16 & 2.90 & 1.92 & 2.33 & 2.30 \\
\hline
\end{tabular}

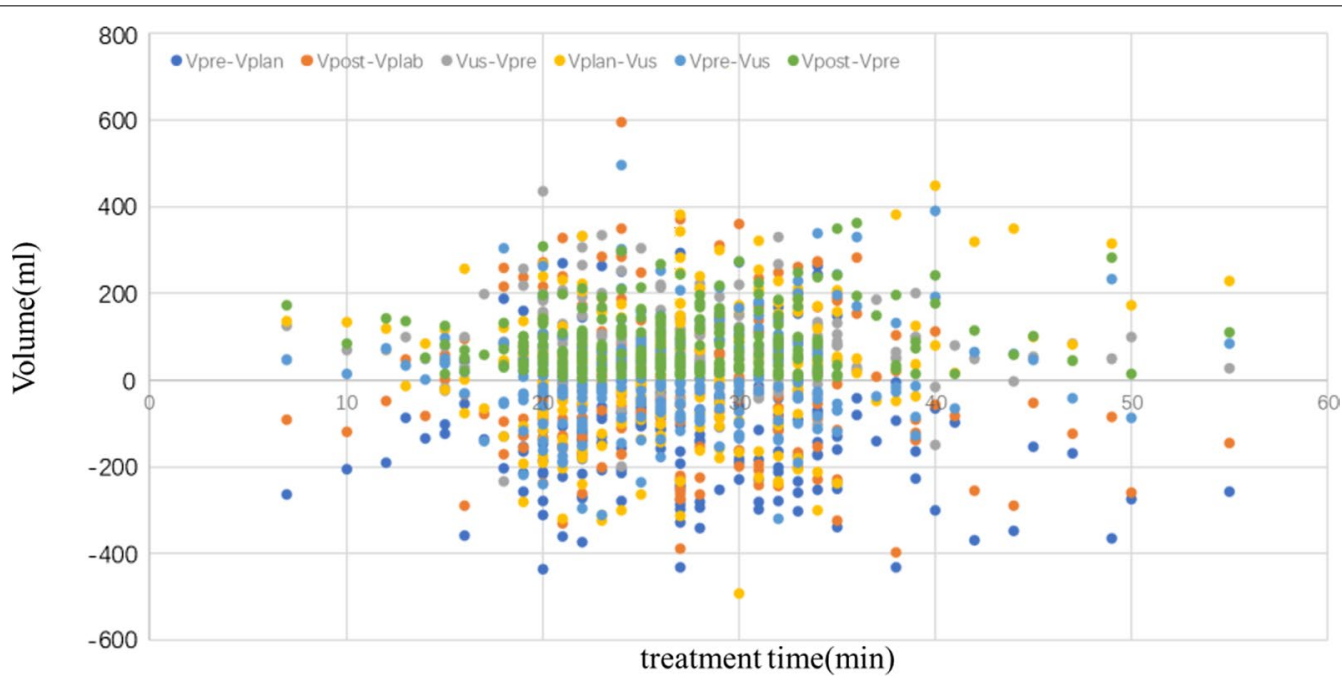

Fig. 3 Distribution of bladder volume with treatment time. The Vus: the bladder volume of US scanner measured; Vpre: the bladder volume of MRI scanner measured before treatment; Vpost: the bladder volume of MRI scanner measured after teatment. Vplan: the bladder volume of CT simulation scan 


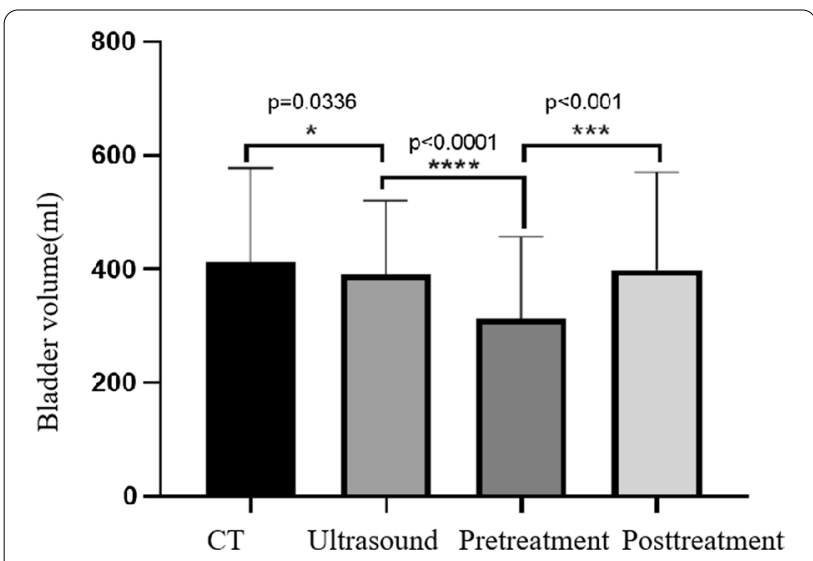

Fig. 4 The distribution of bladder volume under different measurements.There was no significant statistical difference between ultrasound scan and the post treatment scan.One asterisk mean that the $p$ value was less than 0.01.Three asterisks mean that the $p$-value was less than 0.001 .Four asterisks mean that the $p$-value was less than 0.0001

is statistically different from the Vpre (the volume of MRI scanner measured before treatment)and Vpost (the volume of MRI scanner measured after teatment).

The maximum mean directional displacements of the bladder walls for the 43 patients over the scan for the full bladders were $10.8 \mathrm{~mm}$ superiorly, $1.5 \mathrm{~mm}$ inferiorly, $3.19 \mathrm{~mm}$ anteriorly, $3.43 \mathrm{~mm}$ posteriorly, $2.74 \mathrm{~mm}$ to the left and $2.48 \mathrm{~mm}$ to the right. Largest displacements are found in the cranial-anterior direction. Average displacement per treatment fraction was $3.6 \mathrm{~mm}$ in that direction. In $15.6 \%$ of the cases, we found a dis-placement equal or more than $14 \mathrm{~mm}$ in the cranial-anterior direction. In the AP and CC direction the group-mean was significantly different from $0(\mathrm{p}<0.05)$, indicating a preferred direction for the systematic intra-fraction displacements. The movement of the bladder during treatment and the resulting cervical-uterine movement seems to be a reasonable explanation. A similar trend was observed in the $\mathrm{AP}$ and $\mathrm{CC}$ direction.

\section{Discussion}

Accurately accounting for daily uncertainties in target position is an important goal in treating cervical cancer [12]. Uncertainties can arise due to setup variation and both inter- and intra-fraction motion [13]. While increasingly rapid treatment times may mitigate the effects of intrafraction motion, inter-fraction motion is generally addressed by encompassing the target with a planning margin[14]. Presently, quantitative evidence supporting recommended planning margins for intact cervical cancer remains sparse, and the effects of inter-fraction changes on CTV coverage are not fully understood [15-17].

It has been shown that the variation in initial bladder volume was large mean SD $70.63 \mathrm{cc}$, despite the fact that consistent drinking and voiding instructions were followed prior to acquisition. This could be due to several effects. First, we found that some patients (No. 4, 7,18,26, and 33) had difficulties completing the whole treatment process. Second, the waiting time before the start of a treatment was not always equal, and this could the main reason in variation in initial volume.

This study is, to our knowledge, the first to use daily pre- and post-fraction MRI scans to quantify changers in bladder and uterus motions. The results showed that inter-fraction and intra-fraction cervix-uterus motion were considerable in each treatment. The average intrafraction (inter-fraction) displacement of the group was $6.11 \mathrm{~mm}(5.9 \mathrm{~mm})$ in the AP direction and $11.5 \mathrm{~mm}$ $(10.3 \mathrm{~mm})$ in the $\mathrm{CC}$ direction. As shown in Fig. 4, there is a certain difference between the volume measured by ultrasound and the volume measured by planned CT. We currently lack effective means to ensure the consistency of bladder volume. At the same time, it can also be seen that the bladder volume changes significantly with the treatment process.

Individual patient displacements may be even larger and extend more than $10 \mathrm{~mm}$. In this study, we also observed that there was a significant correlation between bladder volume difference and cervical-uterine displacement $(r=0.61, p<0.01)$. Obviously, variations in the position and shape of the bladder were primarily caused by changes in bladder filling. As many studies have shown that MR-guided daily-adaptive radiotherapy seems a promising approach for minimizing treatment uncertainties and to improve treatment outcome. Nicosia et al. [18] found MR-guided daily-adaptive SBRT seems a feasible and accurate strategy for treating prostate cancer with ablative doses. The MR-guided strategy provides a comparable level of accuracy and acceptable real-dose distribution over treatment fractions. Francesco et al. [19] using 1.5 T MR-guided radiotherapy to assess daily variations for both target coverage and organs-at-risk. The study found that daily-adaptive can improve single intestinal loop sparing for lymph-nodal oligometastases. The same team also study the organ motion is a crucial feature for prostate SBRT. They shown that MRI-Linac is a new frontier in radiation oncology in showing visualization of the real-time anatomy of the patient [20, 21].

As other investigators have found [10, 22], we observed significant motions in bladder volume and uterus. Agreements to ensure that these organs are consistent in size will help reduce the source of CTV location changes. For interfraction motion, Yee et al. [23] found in a landmark 
study of bladder cancer CBCT that the movement is the most significant in anteriorly. Without daily imaging guidance, a large part of the target volume may be lost. Haripotepornkul et al.[24] using cervical implanted markers, daily $\mathrm{kV}$ imaging was used to study the intrasegmental movement of patients with cervical cancer throughout the IMRT process. An intermediate marker offset of $2-4 \mathrm{~mm}$ is observed in any given direction, which is smaller than our analysis, especially in the AP direction. However, this can be explained because the markers only represent the position of the cervix, and the cervix is affected by changes in bladder filling smaller than the uterus motion [8].Chen et al. found that the largest movement was found at the bottom of the uterus over a time range of $31 \mathrm{~min}$, averaging $1.1 \mathrm{~mm}$ in the AP direction and $3.1 \mathrm{~mm}$ in the CC direction [25]. This is smaller than what we found, however, it can be explained that we only include patients with large uterine tip displacement measured in full and empty bladder CT scans before treatment [26]. In addition, we would like to point out that we analyzed the scans in pairs, that is, we compared the pre-and post- MRI and CBCT scans of each part. In this way, the effect is mainly reduced to the interpretation difference between pre- and post- image scans. In addition, the accuracy of non-rigid registration used to measure intra-graded motion may be a potential source of error [27]. However, we have seen that this error is very small, so its effect on the observed internal motion is limited. In this study, we used pre-and post-fractionated CBCT scans to quantify the shape of cervix and uterus, and bladder filling, and intra-fractionated changes in patient settings. There is almost no change in the amount of exercise set by the patient. The movement of cervix and uterus is quite large, which is related to bladder filling [28]. The gradual cervical-uterine movement should not be ignored, especially when designing daily planning strategies. The maximum mean directional displacements of the bladder walls over the 43 patients over the scan for the full bladders were $10.8 \mathrm{~mm}$ superiorly, $1.5 \mathrm{~mm}$ inferiorly, $3.19 \mathrm{~mm}$ anteriorly, $3.43 \mathrm{~mm}$ posteriorly, $2.74 \mathrm{~mm}$ to the left and $2.48 \mathrm{~mm}$ to the right. Largest displacements are found in the cranial-anterior direction. Average displacement per treatment fraction was $3.6 \mathrm{~mm}$ in that direction. Statistically significant differences were seen in the posterior, left and right displacements but were quantitatively small.

Patient factors may lead to inter-and intra-temporal changes in the size and position of the bladder. Cervical cancer, especially in patients receiving radiation therapy, usually occurs in the elderly. Despite formal recommendations, deterioration in bladder and renal function may limit a patient's ability to continuously empty the bladder and may also affect the rate at which urine fills the bladder [29]. Adamson and $\mathrm{Wu}[30]$, in a study of pretreatment and posttreatment $\mathrm{CBCT}$ in prostate cancer patients, found that the median bladder increase was $14 \%$. As expected, we found that the largest proportion of bladder volume increase before and after treatment was in patients with small bladder before treatment. This may simply reflect a relatively constant rate of urine production; therefore, patients with a smaller bladder before treatment have a relatively larger increase in volume than patients with a larger bladder before treatment. This suggests that a larger bladder may require a smaller edge than a smaller preconditioned bladder if the CTVPTV edge is personalized to take into account intra-segmented movement. Although this hypothesis is logical, it needs to be confirmed by further research.

\section{Abbreviations}

EBRT: External beam radiotherapy treatment; CBCT: Cone beam computed tomography; CTV: Clinical target volume; FIGO: International federation of gynaecology and obstetrics; US: Ultrasound; FOV: Filed of view; TR: Repetition time; TE: Echo time; TPS: Treatment planning system; SD: Standard deviation.

\section{Acknowledgements}

Not applicable.

\section{Authors' contributions}

Manuscript: XL, LZW, ZJL, YY; Sample acquisition and patient cohort: ZC, JMZ, $J J Z, P L, X L ; S t a t i s t i c a l$ analysis: ZJL. All authors read and approved the final manuscript.

\section{Funding}

This work was supported in part National Natural Science Foundation of China under Grants 82102173; National Key Research and Development Program of China (2016YFC0105106); Academic promotion program of Shandong First Medical University (2019LJ004), Jinan Science and Technology Development Plan(201907108), and by Taishan Scholars Program of Shandong Province, China (Grant NO. ts20120505).

Availability of data and materials

Not applicable.

\section{Declarations}

Ethical approval and consent to participate

All patients gave informed consent to participate.

Consent for publication

Not applicable.

Competing interests

The authors declare no competing interests.

Received: 20 July 2021 Accepted: 6 September 2021

Published online: 17 September 2021

References

1. Cohen PA, Jhingran A, Oaknin A, et al. Cervical cancer. Lancet. 2019;393(10167):169-82.

2. Sturdza A, Pötter R, Fokdal LU, Haie-Meder C, Tan LT, Mazeron R, Petric P, Šegedin B, Jurgenliemk-Schulz IM, Nomden C, Gillham C, McArdle O, Van Limbergen E, Janssen H, Hoskin P, Lowe G, Tharavichitkul E, Villafranca E, Mahantshetty U, Georg P, Kirchheiner K, Kirisits C, Tanderup K, Lindegaard 
JC. Image guided brachytherapy in locally advanced cervical cancer: improved pelvic control and survival in RetroEMBRACE, a multicenter cohort study. Radiother Oncol. 2016;120(3):428-33.

3. Padgett KR, Simpson G, Asher D, Portelance L, Bossart E, Dogan N. Assessment of online adaptive MR-guided stereotactic body radiotherapy of liver cancers. Phys Med. 2020;77:54-63.

4. Mahmoud O, Kilic S, Khan AJ, Beriwal S, Small W Jr. External beam techniques to boost cervical cancer when brachytherapy is not an optiontheories and applications. Ann Transl Med. 2017;5(10):207.

5. Stolnicu S, Hoang L, Soslow RA. Recent advances in invasive adenocarcinoma of the cervix. Virchows Arch. 2019;475(5):537-49.

6. Srivastava A, Datta NR. Brachytherapy in cancer cervix: Time to move ahead from point A? World J Clin Oncol. 2014;5(4):764-74.

7. Kunos CA. Novel radiosensitization strategies in uterine cervix cancer. Semin Radiat Oncol. 2020;30(4):281-90.

8. Ríos I, Vásquez I, Cuervo E, Garzón Ó, Burbano J. Problems and solutions in IGRT for cervical cancer. Rep Pract Oncol Radiother. 2018;23(6):517-27.

9. Rigaud B, Simon A, Gobeli M, Lafond C, Leseur J, Barateau A, Jaksic N, Castelli J, Williaume D, Haigron P, De Crevoisier R. CBCT-guided evolutive library for cervical adaptive IMRT. Med Phys. 2018:45(4):1379-90.

10. Maemoto H, Toita T, Ariga T, Heianna J, Yamashiro T, Murayama S. Predictive factors of uterine movement during definitive radiotherapy for cervical cancer. J Radiat Res. 2017;58(3):397-404.

11. Foroudi F, Wong J, Kron T, et al. Online adaptive radiotherapy for muscleinvasive bladder cancer: results of a pilot study. Int J Radiat Oncol Biol Phys. 2011:81:765-71.

12. Patni N, Burela N, Pasricha R, Goyal J, Soni TP, Kumar TS, Natarajan T. Assessment of three-dimensional setup errors in image-guided pelvic radiotherapy for uterine and cervical cancer using kilovoltage conebeam computed tomography and its effect on planning target volume margins. J Cancer Res Ther. 2017;13(1):131-6.

13. Guerreiro F, Seravalli E, Janssens GO, van de Ven CP, van den HeuvelEibrink MM, Raaymakers BW. Intra- and inter-fraction uncertainties during IGRT for Wilms' tumor. Acta Oncol. 2018;57(7):941-9.

14. Tyagi N, Lewis JH, Yashar CM, Vo D, Jiang SB, Mundt AJ, Mell LK. Daily online cone beam computed tomography to assess interfractional motion in patients with intact cervical cancer. Int J Radiat Oncol Biol Phys. 2011;80(1):273-80.

15. Wang X, Yu M, Wang J, Zhong R, Shen Y, Zhao Y, Li Z, Bai S, Xu F. An assessment of interfractional bladder, rectum and vagina motion in postoperative cervical cancer based on daily cone-beam computed tomography. Mol Clin Oncol. 2016;4(2):271-7.

16. Heijkoop ST, LangerakTR, Quint S, Bondar L, Mens JW, Heijmen BJ, Hoogeman MS. Clinical implementation of an online adaptive plan-ofthe-day protocol for nonrigid motion management in locally advanced cervical cancer IMRT. Int J Radiat Oncol Biol Phys. 2014;90(3):673-9.

17. Lim K, Kelly V, Stewart J, Xie J, Cho YB, Moseley J, Brock K, Fyles A, Lundin A, Rehbinder $\mathrm{H}$, Milosevic M. Pelvic radiotherapy for cancer of the cervix is what you plan actually what you deliver? Int J Radiat Oncol Biol Phys. 2009;74(1):304-12.

18. Nicosia L, Sicignano G, Rigo M, Figlia V, Cuccia F, De Simone A, Giaj-Levra N, Mazzola R, Naccarato S, Ricchetti F, Vitale C, Ruggieri R, Alongi F. Daily dosimetric variation between image-guided volumetric modulated arc radiotherapy and MR-guided daily adaptive radiotherapy for prostate cancer stereotactic body radiotherapy. Acta Oncol. 2021;60(2):215-21.

19. Cuccia F, Rigo M, Gurrera D, Nicosia L, Mazzola R, Figlia V, Giaj-Levra N, Ricchetti F, Attinà G, Pastorello E, De Simone A, Naccarato S, Sicignano $G$, Ruggieri R, Alongi F. Mitigation on bowel loops daily variations by 1.5-T MR-guided daily-adaptive SBRT for abdomino-pelvic lymph-nodal oligometastases. J Cancer Res Clin Oncol. 2021.

20. Mazzola R, Sicignano G, Cuccia F, Vitale C, Rigo M, Giaj-Levra N, Nicosia L, Figlia V, Ricchetti F, Attinà G, Pastorello E, De Simone A, Gurrera D, Naccarato S, Ruggieri R, Alongi F. Impact of hydrogel peri-rectal spacer insertion on seminal vesicles intrafraction motion during 1.5 T-MRI-guided adaptive stereotactic body radiotherapy for localized prostate cancer. Br J Radiol. 2021;20:20210521.

21. Cuccia F, Mazzola R, Nicosia L, Figlia V, Giaj-Levra N, Ricchetti F, Rigo M, Vitale C, Mantoan B, De Simone A, Sicignano G, Ruggieri R, Cavalleri S, Alongi F. Impact of hydrogel peri-rectal spacer insertion on prostate gland intra-fraction motion during 1.5 T MR-guided stereotactic body radiotherapy. Radiat Oncol. 2020;15(1):178.

22. Eminowicz G, Rompokos V, Stacey C, Hall L, McCormack M. Understanding the impact of pelvic organ motion on dose delivered to target volumes during IMRT for cervical cancer. Radiother Oncol. 2017;122(1):116-21.

23. Yee $D$, Parliament $M$, Rathee $S$, et al. Cone beam CT imaging analysis of interfractional variations in bladder volume and position during radiotherapy for bladder cancer. Int J Radiat Oncol Biol Phys. 2010;76:1045-53.

24. Haripotepornkul NH, Nath SK, Scanderbeg D, Saenz C, Yashar CM. Evaluation of intra- and inter-fraction movement of the cervix during intensity modulated radiation therapy. Radiother Oncol. 2011;98(3):347-51.

25. Chen MF, Tseng CJ, Tseng CC, Kuo YC, Yu CY, Chen WC. Clinical outcome in posthysterectomy cervical cancer patients treated with concurrent Cisplatin and intensity-modulated pelvic radiotherapy: comparison with conventional radiotherapy. Int J Radiat Oncol Biol Phys. 2007;67:1438-44.

26. Ahmad R, Hoogeman MS, Bondar M, Dhawtal V, Quint S, De Pree I, Mens JW, Heijmen BJ. Increasing treatment accuracy for cervical cancer patients using correlations between bladder-filling change and cervix-uterus displacements: proof of principle. Radiother Oncol. 2011;98(3):340-6.

27. Datteri RD, Liu Y, D'Haese PF, Dawant BM. Validation of a nonrigid registration error detection algorithm using clinical MRI brain data. IEEE Trans Med Imaging. 2015;34(1):86-96

28. Pfisterer MH, Griffiths DJ, Schaefer W, et al. The effect of age on lower urinary tract function: a study in women. J Am Geriatr Soc. 2006;54:405-12.

29. Heppner TJ, Tykocki NR, Hill-Eubanks D, Nelson MT. Transient contractions of urinary bladder smooth muscle are drivers of afferent nerve activity during filling. J Gen Physiol. 2016;147(4):323-35.

30. Adamson J, Wu Q. Inferences about prostate intrafraction motion from pre- and posttreatment volumetric imaging. Int J Radiat Oncol Biol Phys. 2009;75:260-7

\section{Publisher's Note}

Springer Nature remains neutral with regard to jurisdictional claims in published maps and institutional affiliations.
Ready to submit your research? Choose BMC and benefit from:

- fast, convenient online submission

- thorough peer review by experienced researchers in your field

- rapid publication on acceptance

- support for research data, including large and complex data types

- gold Open Access which fosters wider collaboration and increased citations

- maximum visibility for your research: over 100M website views per year

At BMC, research is always in progress.

Learn more biomedcentral.com/submissions 